American Journal of Applied Sciences 4 (8): 576-583, 2007

ISSN 1546-9239

(C) 2007 Science Publications

\title{
Development and Early Score Validation of the Malaysian Educator's Information Technology Attitude Scale (MEITAS)
}

\author{
Wong Su Luan \\ Department of Science and Technical Education, Faculty of Educational Studies Universiti Putra \\ Malaysia, 43400 Serdang, Selangor, Malaysia
}

\begin{abstract}
The purpose of this study was to develop and provide initial validation evidence for an instrument to measure educators' attitudes toward IT. Data were collected from 817 participants comprising both pre and in-service teachers in four phases. Two separate factor analyses were conducted for the pre-service teacher data and in-service teacher data. Principle component analysis, with varimax rotation, suggested three distinct constructs: affect, perceived usefulness and behaviour. The scores of the instrument also showed high reliability.
\end{abstract}

Key words: Attitudes, Information Technology, Educators

\section{INTRODUCTION}

Information technology (IT) has brought many changes to the area of education. It has revolutionized the way students learn and how teachers teach in the classrooms. Indeed, the permeation of IT into classrooms has created the opportunities for students to be active learners and allowed instructors to be facilitators ${ }^{[1]}$.

Teachers become aware that they cannot continue with the traditional mode of learning when they are in an IT rich environment ${ }^{[2]}$. Teachers of today will have to use new instructional approaches as traditional teaching styles may not be relevant in today's education system ${ }^{[3,4]}$. They will have to move away from the "stand and deliver" teaching methods because technology fosters the use of more student centred learning strategies ${ }^{[5]}$.

In a student centred learning environment, students are expected to be creative and critical thinkers; and active players with teamwork skills, to be successful learners in the $21^{\text {st }}$ century ${ }^{[3]}$. Teachers, therefore, will have to gear their teaching styles toward methods that emphasise on collaborative learning, problem solving and critical thinking. All teachers will have to be proficient in IT because they will have new roles to play in such learning environments.

The roles expected of teachers today should, therefore, take into account computer-based ways of tracking down information, retrieving information through the media, decoding various kinds of information, using computer systems to find how different fields knowledge relate to one another, showing students how to network and to help students use various telecommunication devices, including virtual and real time systems. Bitter and Yohe ${ }^{[6]}$ suggested that to meet the needs of their students effectively, teachers must be proficient, critical users of present educational technologies and should be able to address the limitations and future possibilities of these technologies.

Yildrim ${ }^{[7]}$ warned it is unlikely that teachers will be able to transfer their technology skills, let alone encourage the use of technology among students if teachers have negative attitudes toward technology. Woodrow $^{[8]}$ stressed that the importance of teachers' attitudes should be accessed because attitudes can influence teachers' acceptance of computers and their future behavior regarding use. Yuen and $\mathrm{Ma}^{[9]}$ succinctly summarised the need to assess teachers' attitudes towards IT to determine the effectiveness of IT training courses.

To date, searching in the literature has revealed only one psychometrically sound scale measuring attitudes toward IT. Knezek and Christensen ${ }^{[10]}$ developed a questionnaire to measure teachers' attitudes toward IT (TAT) comprising 50 semantic differential items. The items were measured in terms of a 7-point bipolar adjective scale. The constructs measured how respondents felt about the electronic mail (e-mail), World Wide Web (WWW), multimedia, computers for professional productivity and use of computers in classrooms. According to the authors, items measuring the use of IT to improve teacher productivity were also incorporated into the instrument.

Corresponding Author: Wong Su Luan, Department of Science and Technical Education, Faculty of Educational Studies, Universiti Putra Malaysia, 43400 Serdang, Selangor, Malaysia 
Although the reliability evidence of TAT was $\operatorname{good}^{[10,11]}$, the author felt that it was important a new instrument comprising Likert scale items be developed for several reasons. First, researchers will be able to measure teachers' attitudes toward IT if they preferred a Likert scale measure or if they were unfamiliar with semantic differential items. In addition, Stone ${ }^{[12]}$ stated that Likert's ${ }^{[13]}$ summative method is the most popular approach for measuring attitude. Second, an instrument unique to the Malaysian culture and setting is urgently needed as there is no instrument specifically to measure Malaysian educator's attitudes toward IT. Third, but more importantly, the new instrument would provide a measure of three important constructs of attitudes: affect, cognition and behaviour.

Attitude is generally classified according to three categories of attitude responses which are affect, cognition and behaviour or behavioural intention ${ }^{[14,15]}$. According to Ajzen ${ }^{[14]}$, affect is related to the evaluation of and the feelings toward the attitude object while cognition reflects the perception of and information about the attitude object and lastly behavioural or behavioural intention are commitments, and actions toward the attitude object. The search of the literature did not reveal any study that defined clearly the meaning of attitudes toward IT. There were, however, several definitions related to attitudes toward computers in the literature. Because computer is a part of IT, the author thought that it would be worth to look at these studies.

Kay $^{[16]}$ and Selwyn ${ }^{[17]}$ proposed four subscales of computer attitudes. The subscales measured affection (how an individual feels towards computers), perceived usefulness (the extent to which an individual believes using computers will enhance job performance), perceived control (perceived ease or difficulty of using computers) and behaviour (behavioural intentions and actions with respect to computers). The most recent attitudes toward the computer instrument in the literature is by Shaft, Sharfman and $\mathrm{Wu}^{[18]}$. The instrument was developed consistent with the theoretical argument that attitude is made up of the affective, behavioural and cognitive components.

In the context of attitudes toward IT in this study, affect refers to positive or negative feelings toward IT. At the cognition level, it refers to how teachers perceive IT, such as perceiving the usefulness of productivity tools, the Internet and e-mail while behaviour reflects teachers' aversion toward IT.

Design of The Study: Four phases were involved in the development and early validation of the instrument. Scale development and content validation were carried out in phase one. Content validity was repeated in phases two and three. Both these phases were also to determine the internal consistency of the items and to carry out item discriminant. While the last phase was to establish construct validity. A total of 817 participants were involved in all four phases of the study. The participants were pre and in-service teachers. Preservice teachers were from a premier university and four teacher training colleges while in-service teachers were from schools located in the central and southern regions of the country.

Phase One: This phase was to develop new items and to modify existing items, while the content validity of the instrument was determined as well. The items were also improved at this phase before they were further tested.

Scale development and content validity: The first step involved examining Likert scale items from existing instruments that purport to measure computer attitudes. As noted earlier, the computer is an important component of IT and the review of literature has found several established instruments that measure computer attitudes. These are the Computer Attitude Scale developed by Loyd and Gressard ${ }^{[19]}$, Computer Attitude Questionnaire by Christensen and Knezek ${ }^{[20]}$, Computer Attitude Measure by $\mathrm{Kay}^{\left[{ }^{6]}\right.}$ and Computer Attitude Scale by Selwyn ${ }^{[17]}$ and the latest instrument, Attitude towards Computers Instrument by Shaft et al. ${ }^{[18]}$. Of these, the scales by Christensen and Knezek ${ }^{[20]}$ and $\mathrm{Kay}^{[20]}$ were developed for teachers while the ones by Loyd and Gressard ${ }^{[19]}$ and Selwyn ${ }^{[17]}$ were for students. The instrument by Shaft et $\mathrm{al}^{[18]}$ was developed for users in a non educational setting. The focus of all the instruments was the general attitudes relating to the use of computers. Although the items measured computers per se, they gave the author ideas for the content of the new scale. Forty-five items from the new scale were loosely derived from these instruments; 14 items were specifically adopted and adapted with permission from Loyd and Gressard's ${ }^{[19]}$ Computer Attitude Scale and Christensen and Knezek's ${ }^{[11]}$ Teachers' Attitudes Toward Computers Questionnaire. At the same time, careful consideration was taken to ensure that the items were within the framework grounded on the work of Ajzen $^{[14]}$.

The items measured attitudes toward e-mail and WWW, software applications, software applications in general, computer and IT in general. The fourteen 
statements that were adopted and adapted from Loyd and Gressard's ${ }^{[19]}$ Computer Attitude Scale and Christensen and Knezek's ${ }^{[11]}$ Teachers' Attitudes Toward Computers Questionnaire were translated into the Malaysian national language (Malay Language). As the five choice Likert scale was used, the scale ranged from "strongly agree $=5$, agree $=4$, not sure $=3$, disagree $=2$, strongly disagree $=1$ " for positive items and "strongly agree $=1$, agree $=2$, not sure $=3$ disagree $=4$, strongly disagree $=5$ " for negative items.

New items were written in both positive and negative directions to control for response set. A panel of six expert judges with expertise in educational technology and instructional technology validated the instrument and agreed unanimously that the contents were appropriate. A double back translation was done on items from the Computer Attitude Scale and Teachers' Attitudes Toward Computers Questionnaire which were originally in English. The translated items in the Malay Language were given to two English language teachers. The teachers were asked to translate the items back into English. The translated items were then given to an English language professor to verify the consistency of the translation. The English language professor agreed that the translations done by both teachers were accurate and matched the original version of the items.

Phases Two and Three: The purpose of both phases was to further determine the content validity of the instrument as well as to determine the reliability of scores. Item discriminant was also conducted at both stages. Kehoe ${ }^{[21]}$ stated that the item discrimination coefficient is the correlation between the item score and the total score. Item discriminant was determined through Pearson correlation because Friedenberg ${ }^{[22]}$ recommended that this correlation be used when items are in Likert's scale form. Based on the feedback obtained from the participants in phase two, several items were rewritten for clarity and brevity. In phase three, the revised instrument was tested again. The content validity of the revised instrument was reestablished by two of the original expert judges.

Participants: For phase two, 18 student teachers from a leading university took part in the survey. Their ages ranged from 19 to 30 years old $(\mathrm{M}=21.12 ; \mathrm{SD}=1.89)$. In a move to address the possible problem of having the small number of participants, the researcher carried out another survey round on a bigger sample $(\mathrm{N}=39)$ in phase three. Their ages were between 20 and $25(\mathrm{M}=$ 20.53; $\mathrm{SD}=1.04$ ). A slightly modified version was used in phase three after it had been revised for clarity and brevity. Two sets of data were collected in a time span of three months.

Results: Aiken [23] recommended that an item with a value of .30 or higher be accepted in an instrument. For that reason, items with a discriminant index value greater than .30 were kept because they were considered to be able to discriminate between participants who had positive and negative attitudes. Six items were discarded in phase two while another five items were removed in phase three. After item reduction, the Cronbach alpha values recorded were .90 and .93 for phases two and three respectively. In total, 34 items were retained after item discrimination.

Phase Four: Data from this phase were used to establish the factor structure of the scale. This was an attempt to establish construct validity. Two sets of data (pre and in-service teachers) were factor analysed separately using principle component analysis (PCA) with a varimax rotation. The main purpose of testing the instrument with pre and in-service teachers was to allow the author to develop a valid instrument for both groups of teachers.

Participants: For this stage, 760 participants were involved. Data were collected nationwide which included 547 pre-service teachers (Group 1) and 213 inservice teachers (Group 2). The mean age of pre-service teachers, was 26.36 (S.D. $=6.951)$ while the mean age for in-service teachers was 37.61 (S.D.= 6.378).

Results: The 34 items were subjected to separate PCA according to the data collected from two different groups. Prior to performing PCA, the suitability of both sets of data for factor analysis were assessed. The Kaiser-Meyer-Olkin measure of sampling adequacy was .921 for Group 1 and .918 for Group 2. The values indicated that none of the items violated the assumption of no multicollinearity. Because the the Bartlett's Test of Sphericity was significant $(p<.001)$ for both groups, it supported the factorability of the correlation matrix.

The decision on the number of factors to extract was based on the scree test and latent root criterion as recommended by Hair, Anderson, Tatham and Black ${ }^{[24]}$. Eigen values greater than one were accepted for the latent root criterion. The latent root criterion with a cutoff value of 1.0 for the eigen values suggested seven factors should be retained after running PCA for both groups. All seven factors were found to have eigen values greater than one, accounting for $62.209 \%$ of the variance for Group 1 and $66.952 \%$ of the variance for Group 2 in the item responses. However, Factors 5, 6, 7 for Group 1 and Factors 4, 5, 6, 7 for Group 2 had variances of less than $4 \%$. 
Am. J. Applied Sci., 4 (8): 576-583, 2007

Table 1: Rotated structure coefficients for three factors

\begin{tabular}{lllllll}
\hline Items & Factor 1 & & Factor 2 & & Factor 3 & \\
& Gr1 & Gr2 & Gr1 & Gr2 & Gr1 & Gr2 \\
\hline A2 & .742 & .726 & .127 & .178 & .201 & .251 \\
A3 & .714 & .742 & .180 & .166 & .121 & .208 \\
A6 & .701 & .643 & .100 & .148 & .249 & .484 \\
C2 & .688 & .729 & .147 & .137 & .162 & .226 \\
C7 & .668 & .741 & .226 & .051 & .052 & .077 \\
A1 & .662 & .671 & .177 & .246 & .255 & .279 \\
A10 & .656 & .598 & .061 & .171 & .244 & .426 \\
C11 & .628 & .647 & .029 & .087 & -.009 & .028 \\
A11 & .622 & .634 & .087 & .110 & .207 & .269 \\
A7 & .604 & .474 & .117 & .256 & .374 & .514 \\
A12 & .594 & .653 & .145 & .258 & .439 & .299 \\
A4 & .578 & .505 & .120 & .176 & .382 & .503 \\
C5 & .563 & .549 & .162 & .181 & .196 & .349 \\
A9 & .562 & .594 & .162 & .193 & .394 & .528 \\
C1 & .491 & .345 & .143 & .359 & .200 & .299 \\
C10 & .441 & .548 & .350 & .121 & .031 & .307 \\
C9 & .313 & .646 & .288 & .138 & .087 & .229 \\
U8 & .123 & .064 & .726 & .736 & .112 & .253 \\
U7 & .149 & .105 & .707 & .697 & .120 & .170 \\
U6 & .095 & .235 & .703 & .560 & -.018 & .118 \\
U11 & .110 & .176 & .693 & .662 & .101 & .055 \\
U10 & .079 & .142 & .676 & .747 & .163 & .185 \\
U12 & .111 & .122 & .670 & .701 & .083 & .114 \\
U5 & .129 & .132 & .647 & .689 & .053 & .127 \\
U9 & .061 & .139 & .644 & .792 & .114 & .118 \\
U4 & .102 & .121 & .449 & .534 & .047 &. .029 \\
U2 & .169 & .055 & .435 & .643 & .005 & .089 \\
V6 & .173 & .238 & .093 & .209 & .784 & .770 \\
V5 & .228 & .191 & .037 & .151 & .761 & .777 \\
V4 & .246 & .271 & .187 & .163 & .722 & .627 \\
V1 & .226 & .262 & .082 & .014 & .692 & .634 \\
V10 & .198 & .201 & .105 & .148 & .687 & .746 \\
V3 & .433 & .327 & .127 & .189 & .551 & .630 \\
A8 & .515 & .491 & .135 & .197 & .524 & .534 \\
$*$ & 21.05 & 21.79 & 13.92 & 15.96 & 12.86 & 15.88 \\
\hline
\end{tabular}

*Percentage of variance accounted for

Gr 1= pre-service teachers; Gr 2= in-service teachers

An inspection of the screeplot obtained for both groups seemed to suggest a break after the third and fourth component. Therefore, three and four factor extractions using varimax rotation were tested to determine which had a better fit. The three factor extraction was found to be a better fit. The items associated with the corresponding factors are shown in Table 1. Table 1 shows that the factor structure coeffiecients for Groups 1 and 2 are similar except for Item 20. This item loaded on Factor 1 for Group 1 while it loaded on Factor 3 for Group 2. For this reason, the author decided to delete Item 20. Sixteen items were salient with the first factor. There were 2 positive and 14 negative items. Both positive items had the lowest structure coefficients in Factor 1. Ten items were salient with the second factor. Seven items loaded on the third factor. All items for Factor 2 were in positive form while all items in Factor 3 were in negative form. 
Table 2: Retained items in the final version of MEITAS

\begin{tabular}{|c|c|c|}
\hline Subscale & $\begin{array}{l}\text { Item } \\
\text { number }\end{array}$ & Items \\
\hline \multirow{10}{*}{ 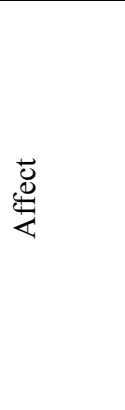 } & A2 & I feel anxious when learning about software. * \\
\hline & A3 & The use of computer software confuses me. $*$ \\
\hline & $\mathrm{C} 2$ & I feel that using a computer is hard for me. * \\
\hline & A6 & The use of a computer gives me a headache.* \\
\hline & $\mathrm{C} 7$ & I am not skilful in using a computer. * \\
\hline & A1 & I feel uncomfortable when using computer software. * \\
\hline & $\mathrm{C} 11$ & $\begin{array}{l}\text { I feel that I take a long time to understand some issues taught in an Information Technology } \\
\text { course. * }\end{array}$ \\
\hline & $\mathrm{C} 10$ & I have high confidence when attending an Information Technology course. \\
\hline & A10 & I sometimes get nervous just thinking about computers. * \\
\hline & C9 & I can get good grades in Information Technology courses. \\
\hline \multirow{9}{*}{ 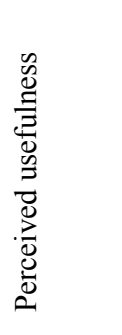 } & $\mathrm{U} 2$ & The use of electronic mail makes it easier to contact my friends. \\
\hline & U4 & The Internet is useful for searching information. \\
\hline & U5 & Word processing software allows me to edit my work more frequently. \\
\hline & U6 & My writing is of quality when using word processing software. \\
\hline & U7 & Database software makes it easier to manage information. \\
\hline & U8 & Database software allows me to keep information neatly. \\
\hline & U9 & My presentation is more effective when using presentation software. \\
\hline & U10 & My presentation is more interesting when using presentation software. \\
\hline & U11 & Spreadsheet software allows me to do calculations easily. \\
\hline \multirow{8}{*}{ 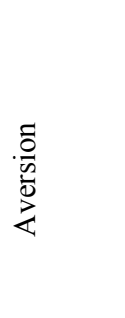 } & U12 & Spreadsheet software allows me to create various charts easily. \\
\hline & A8 & I avoid using a computer because I am afraid of it.* \\
\hline & V1 & Only clever people can use Information Technology. ${ }^{*}$ \\
\hline & V3 & I will never take a job where I have to work with Information Technology.* \\
\hline & V4 & The use of Information Technology prevents me from being creative. * \\
\hline & V5 & Only people who are skilled should use Information Technology. ${ }^{*}$ \\
\hline & V6 & Learning about Information Technology wastes my time. ${ }^{*}$ \\
\hline & V10 & $\begin{array}{l}\text { The time used for learning Information Technology is better spent on learning something else. } \\
*\end{array}$ \\
\hline
\end{tabular}

Table 3: Inter-correlation matrix and reliability coefficients of three factors

\begin{tabular}{|c|c|c|c|c|c|c|}
\hline & \multicolumn{3}{|c|}{ Group 1} & \multicolumn{3}{|c|}{ Group 2} \\
\hline & Factor 1 & Factor 2 & Factor 3 & Factor 1 & Factor 2 & Factor 3 \\
\hline Factor 1 & - & $.410^{*}$ & $.586^{*}$ & - & $.419 *$ & $.687^{*}$ \\
\hline Factor 2 & & - & $.312 *$ & & - & $.420 *$ \\
\hline Factor 3 & & & - & & & - \\
\hline Cronbach's alpha & .867 & .853 & .868 & 906 & .885 & .874 \\
\hline $\begin{array}{l}\text { Overall Cronbach's } \\
\text { alpha }\end{array}$ & & .908 & & & .925 & \\
\hline
\end{tabular}

Factor 1 was named affect which measures participants' negative and positive feelings toward IT, Factor 2 was named perceived usefulness which measures participants' perceptions on the usefulness of IT and Factor 3 was labelled as behaviour which measures participants' aversion toward IT.

Ten items were retained for the first construct to ensure that all three constructs would have almost an equal number of items. This step would also ensure that the total score would not be biased toward any construct. The author also decided to retain both positive items in Factor 1 to balance the number of positive and negative items in the instrument. However, one of the positive items in Factor 1 had quite a low factor loading (.31). This item was still retained because Hair et al. ${ }^{[24]}$ considered structure coefficients greater than .30 to be significant.

Internal Consistency: The final version of the instrument, named the Malaysian Educator Information Technology Attitude Scale (MEITAS) had 27 items. The full items are shown in Table 2. The internal consistency reliability coefficient and the correlations among factors are shown in Table 3. The Cronbach's $\alpha$ 
for all factors for both groups was above .80 , while the Cronbach's $\alpha$ for the overall scale for both groups was above 90 . According to the guidelines provided by DeVellis ${ }^{[25]}$, this is an excellent reliability of scores for a research instrument.

For both groups, the inter-correlation matrix among the three subscales was moderately high and was statistically significant at $p=.01$ (Table 3 ). This means that the subscales are distinct but still inter-correlated with one another. It could, therefore, be concluded that the three factors measure attitudes toward IT in a coherent manner.

Criterion Validity: Criterion validity is defined as the ability of a test to predict performance of another measure ${ }^{[22]}$. One type of criterion validity, concurrent validity measures the current relationship between the predictor and criterion. The scores for predictor and criterion are collected at the same time ${ }^{[26]}$. Selwyn ${ }^{[17]}$ pointed out that the concurrent validity of a scale can be determined by relating the scale scores to an independent criterion.

Participants were asked to indicate their computer experience in the same survey form where data were used to run PCA. It is hypothesised that prior computer experience will have a strong relationship with participants' attitudes toward IT $^{\text {27-31]. A Pearson }}$ correlation analysis was carried out to assess if there was a relationship between prior computer experience and IT attitudes. The relationship was low but statistically significant $(\mathrm{r}=.165)$ at $p<.01$ for Group 1 . The relationship was moderate and statistically significant $(\mathrm{r}=.551)$ at $p<.01$ for Group 2 .

Chang's Test Of Connotatively Consistent Versus Connotatively Inconsistent Items: Of the 27 items retained in the final version, 15 items were connotatively inconsistent (CI) items (negatively worded items) while the rest were connotatively consistent (CC) items (positively worded items). Items of both types were developed for this scale with the assumption that $\mathrm{CI}$ and $\mathrm{CC}$ items bear the same meaning in relation to the underlying construct measured in the instrument. Chang ${ }^{[32]}$, however, warned that making such assumption can be inaccurate. Chang recommended that the means and variances of both types of item should be similar if both types of item exist in the instrument.

In a move to address the concern of the high number of negative worded items in MEITAS, the grand mean and the standard deviation of both types of item were compared. For Group 1, the grand mean and standard deviation of $12 \mathrm{CC}$ items were 4.137 and .436 respectively while the grand mean and standard deviation of $15 \mathrm{CI}$ items were 4.049 and .539 respectively. Even though the mean difference was a mere 0.088 and standard deviation differed by only 0.103 , the t-test showed a statistical significant difference, $t(547)=3.942, P<.001$. The power of this test was high (.88).

For Group 2, the grand mean and standard deviation of $12 \mathrm{CC}$ items were 4.150 and .446 respectively while the grand mean and standard deviation of $15 \mathrm{CI}$ items were 4.014 and .546 espectively. The mean difference was a mere .136 and standard deviation differed by only 0.100 . Again, the ttest showed a statistical significant difference, $t(547)=$ $3.942, P<.001$. The power was also high (.82) for this test.

\section{DISCUSSION}

From the results presented above, the author is confident that MEITAS can provide statistically reliable and valid measure of Malaysian educators' attitudes toward IT. In addition, the instrument was developed in the Malay Language, seemed most appropriate, as it is the national language. The use of Malay Language made it possible for participants to fully understand the entire instrument. For these reasons, the instrument is deemed usable among Malaysian educators.

The item analyses were done in an iterative manner to ensure that the discriminant indices could be improved. The series of two item analyses conducted revealed the items had consistent levels of item discriminant indices.

The reliability estimates were uniformly high and surpassed the minimal consistency guidelines $(>.70)$ recommended by DeVellis ${ }^{[26]}$. The congruence of high estimates across multiple testings showed clearly that the instrument was indeed capable of yielding highly reliable scores that were highly reliable. The reliability estimates exhibited throughout the study proved that the instrument was able to maintain adequate levels of internal consistency.

PCA confirmed that three distinct subscales exist as underlying constructs of MEITAS. This explains the significant correlations that exist between the three constructs. Almost all items retained in the final version exhibited high structure coefficients $(>.40)$ for both groups. Further construct validity was also established when a low but significant relationship was established between the sum scores of the three dimensions and participants' prior computer experience.

Chang's [32] test of $\mathrm{CC}$ items versus $\mathrm{CI}$ items showed a statistically difference between the two types of item. Chang warned that by including negatively 
worded items, the underlying construct of a scale can be altered. Ponterotto, Baluch, Greig and Rivera ${ }^{[33]}$ suggested that an analysis with a large sample size and the high power of the test make it possible for small differences to be significant. The slight difference detected in the mean of this study could, therefore, be because of the function of the large samples used and the resultant power of the statistical analyses conducted $^{[33]}$.

\section{CONCLUSION}

The study reports on the development of a scale to measure educators' attitudes toward IT and its validation processes. Psychometric tests carried out showed evidence of a three-dimensional construct. The first construct was named affect (10 items), the second construct was named perceived usefulness (10 items) and the last construct was labelled as behavioural (7 items). The internal consistency of the three subscales and the results of the PCA strongly suggest that the subscales scores are adequately stable as separate scores. The moderate and significant relationships among the three subscales as well as the moderately high structure coefficients in the PCA strongly indicate that the three subscales share a large amount of common variance. Gressard and Loyd ${ }^{[34]}$ stated that with such correlation and structure coefficients, the total summation of the three scores can be reasonably interpreted to represent a general attitude toward IT among educators. Suffice to say, MEITAS has been shown to be a valid and reliable scale when measuring pre- and in-service teachers' attitudes toward IT.

\section{FUTURE DIRECTIONS}

Because the research involved the development and the early validation of MEITAS, the instrument will be evaluated on a new sample for further construct validity. Data will be collected at the beginning and at the end of an introductory IT course to further establish construct validity. Based on past research ${ }^{[7,29,35,36]}$, it is hypothesised that participants will have more positive attitudes toward IT after completing an introductory IT course. The results obtained will show if the instrument is sensitive enough to discriminate between participants with negative and positive attitudes toward IT. The testretest reliability of the instrument will also be established at this stage to determine the stability of MEITAS.

It should be noted that factor analysis in this study was descriptive or exploratory in nature. It is, therefore, important to conduct confirmatory factor analysis on a new set of samples to assess the extent to which the observed indicators reflect the structure of the underlying constructs. Future work will also include attempts to generate more positive items for the affective and behavioural constructs.

\section{REFERENCES}

1. Anderson, D. K. and W. M. Reed, 1998. The effects of Internet instruction, prior computer experience, and learning style on teachers' Internet attitudes and knowledge. Journal of Educational Computing Research, 19 (3): 227-246.

2. Wang, Y.M., 2002. When technology meets beliefs: preservice teachers' perception of the teacher's role in the classroom with computers. Journal of Research on Technology in Education, 35(1):150-161.

3. Coombs, S.J. and P.Wong, 2000. Supporting student centred learning with IT, in M.Williams (Ed), Integrating Technology into Teaching and Learning: concepts and application. Singapore: Prentice Hall.

4. Hirumi, A., 2002. Student-centered, TechnologyRich Learning Environments (SCenTRLE): operationalizing constructivist approaches to teaching and learning, Journal of Technology and Teacher Education, 10(4): 497-537.

5. Norum, K., R.Grabinger, and J. Duffield, 1999. Healing the universe is an inside job: teachers; views on integrating technology. Journal of Technology and Teacher Education, 7(3):187-203.

6. Bitter, G. and R. L. Yohe, 1989. Preparing teachers for the information age. Educational Technology, 29:2-25.

7. Yildrim, S., 2000. Effects of an educational computing course on preservice and inservice teachers: a discussion and analysis of attitudes and use. Journal of Research on Computing in Education, 32(2): 479-495.

8. Woodrow, J. E. J., 1991. A comparison of four computer attitude scales. Journal Journal of Educational Computing Research, 7:165-187.

9. Yuen, A. H. K., and W. W. K. Ma, 2001. Teachers' computer attitudes: factors influencing the instructional use of computers. International Conference on Computers in Education. Retrieved December 14, 1999 from, http://www.icce2001.org/cd/pdf/P05/CN003.pdf

10. Knezek, G. and R.Christensen, 1997. Internal consistency reliabilities for 14 computer attitude scales. Presented at Society of Information Technology \& Teacher Education (SITE)'s 8th International Conference, Orlando, Florida, April 1997.

11. Knezek, G. and R.Christensen, 1998. Internal consistency reliability for the teachers' attitudes toward information technology questionnaire. Presented at Society of Information Technology \& Teacher Education (SITE)'s 9th International Conference, Washington, DC, March 13, 1998. 
12. Stone, M., 2002. Attitudes, related behaviour and aging. Retrieved May 10, 2004, from http://flash.lakeheadu.ca/ mstones/GEROBOOKat titudes.pdf.

13. Likert, R., 1932. A technique for the measurement of attitudes. New York: Archives of Psychology.

14. Ajzen, I., 1988. Attitudes, personality, and behavior. Chicago, IL: Dorsey Press.

15. Breckler, S.J., 1994. Empirical validation of affect, behaviour and cognition as distinct components of attitudes. Journal of Personality \& Social Psychology. 47(6): 1191-1205.

16. Kay, R., 1993. An exploration of theoretical and practical foundations for assessing attitudes toward computers. Computers in Human Behaviour, 9: 371-386.

17. Selwyn, N., 1997 Students' attitudes toward computers: validation of a computer attitude scale for 16-19 education, Computer Education, 28(1): $35-41$.

18. Shaft, T. M., M. P. Sharfman and W. W. Wu, 2004. A reliability and validity assessment of an attitude toward computers instrument. Computers in Human Behavior, 20(5): 661-689.

19. Loyd, B. H. and C. Gressard, 1984. Reliability and factorial validity of computer attitude scales. Educational and Psychology Measurement, 44: 501-505.

20. Christensen, R., \& G.Knezek, 1996. Constructing the teachers' attitudes toward computers (TAC) questionnaire. ERIC Document Reproduction Service No. ED398244. 21.

21. Kehoe, J., 1995. Basic item analysis for multiplechoice tests. Retrieved September 30, 1999, from http://www.ed.gov/databases/ERIC_Digests/ed398 237.html .

22. Friedenberg, L., 1995. Psychological testing: design, analysis and use. Massachusetts: Simon and Schuster Company.

23.Aiken, L. R., 1994. Psychological testing and assessment. Massachusetts: Allyn and Bacon.

24. Hair, J. F., R. E.Anderson, , R. L. Tatham, and W. C. Black, 1992. Multivariate data analysis with readings. New York: Macmillan Publishing Company.

25. DeVellis, R. F. 1991. Scale development: theory and applications. Newbury Park, CA: SAGE Publications.

26. Barki, H. and J.Hartwick, 1994. Measuring user participation, user involvement and user attitude. MIS Quarterly, 18(1): 59-83.
27. Venkatesh, V. and M.G. Morris, 2000. Why don't men ever stop to ask for directions? gender social influence and their role in technology acceptance and usage behaviour. MIS Quarterly, 24:115-139.

28. Liao, Y.K., 1997. The comparison of inservice and preservice teachers' attitudes toward educational computing in Taiwan. In SITE Conference held in Orlando, Florida, 10-14 March 1998: online proceedings edited by J. Willis and P.William. Va: AACTE. Retrieved May 10 1999, from http://www.coe.uh.edu/insite/elec_pub/HTML1997 re liao.htm.

29. Wild, M., 1995. Pre-Service teacher education programs for information technology: an effective education? Journal of Information Technology in Teacher Education, 4(1): 7-20.

30. Summers, M., 1990a. Starting teacher trainingnew PGCE students and computers. British Educational Research Journal, 16: 79-87.

31. Summers, M., 1990b. New student teachers and computers: an investigation of experiences and feelings. Educational Review, 42: 261-271.

32. Chang, L., 1995. Connotatively consistent and reversed connotatively inconsistent items are not fully equivalent: generalizability study. Educational and Psychological Measurement, 55: 991-997.

33. Ponterotto, J. G., S.Baluch, T. Greig, and L.Rivera, 1998. Development and initial score validation of the teacher multicultural attitude survey. Educational and Psychological Measurement, 58(6): 1002-1016.

34. Gressard, C.P., and B.H. Loyd, 1986. Validation of a new computer attitude scale. Association for Educational Data Systems Journal, 18: 295-301.

35. McFarlane, A. and E. Jared, 1994. Encouraging student teacher confidence in the use of Information Technology. Computers and Education, 22(1): 155-160.

36. Wong, S.L., A. J.Habibah, M. A.Ahmad Fauzi, A. B. Kamariah and S.H. Tang, 2003. Teaching a discrete information technology course in a constructivist learning environment: is it effective for Malaysian pre-service teachers?. Internet and Higher Education. 6(2): 193-204. 